\title{
Projected Life of the SLAC Linac Braze Joints: Braze integrity and corrosion of cooling water hardware on accelerator sections
}

\author{
W.F. Glesener and E. L. Garwin \\ Stanford Linear Accelerator Center \\ 2575 Sand Hill Road \\ Menlo Park, CA 94025
}

\section{Summary}

The objective of this study was to ascertain the condition of braze joints and cooling water hardware from an accelerator section after prolonged use. Metallographic analysis was used to examine critical sites on an accelerator section that had been in use for more than 30 years. The end flange assembly showed no internal operational damage or external environmental effects. The cavity cylinder stack showed no internal operational damage however the internal surface was highly oxidized. The internal surface of the cooling water tubing was uniformly corroding at a rate of about 1 mil per year and showed no evidence of pitting. Tee fitting internal surfaces are corroding at non-uniform rates due to general corrosion and pitting. Remaining service life of the cooling water jacket is estimated to be about 20 years or year 2027. At this time, water supply pressure will exceed allowable fitting pressure due to corrosion of tubing walls.

\section{Overview}

The aim of this study was to determine the integrity of an accelerator section after prolonged operation. An original 10-foot accelerator section, in use from May 21, 1966 to February 7, 1997 was selected. The 40 plus year old section was in service for more than 30 years (11,220 days) and is \#327 from Linac location 4-1c.

Bulk metallographic analysis was used to examine numerous braze joints and critical locations near the RF input coupler. Location and hardware can be classified into 3 main groups: 1) an end flange assembly 2) cavity cylinder stack and 3) cooling water tubing and fittings. Hardware is identified by assembly stock numbers, such as (AD 750-155), or individual drawing numbers e.g. (PF 751-043).

We examined the disc-loaded waveguide assembly to determine the operational and environmental effects on the inner and outer surfaces of the hardware and use the results to estimate remaining service life. Several microphotographs are included in this report to represent typical conditions. Many additional photos are available for analysis and review. 


\section{End Flange Assembly}

In order to facilitate welding of adjacent accelerator sections an end flange assembly is required. The assembly had to be brazed together in two steps. Step 1 joined a stainless steel, type 347, flared cup end flange (PF 750-157) to a type 304 stainless steel stiffening ring (PF 750-156) with 100\% copper filler metal. Melting point of the $\mathrm{Cu}$ filler metal is $1083^{\circ} \mathrm{C}$.

Step 2 joined the previously brazed weld flange assembly (AD 750-155) to an OFHC copper end plate coupler (PF 750-154). See Photo 1 below. The braze alloy used in this location was $65 \%$ copper and $35 \%$ gold with a melting point of $1010^{\circ} \mathrm{C}$.

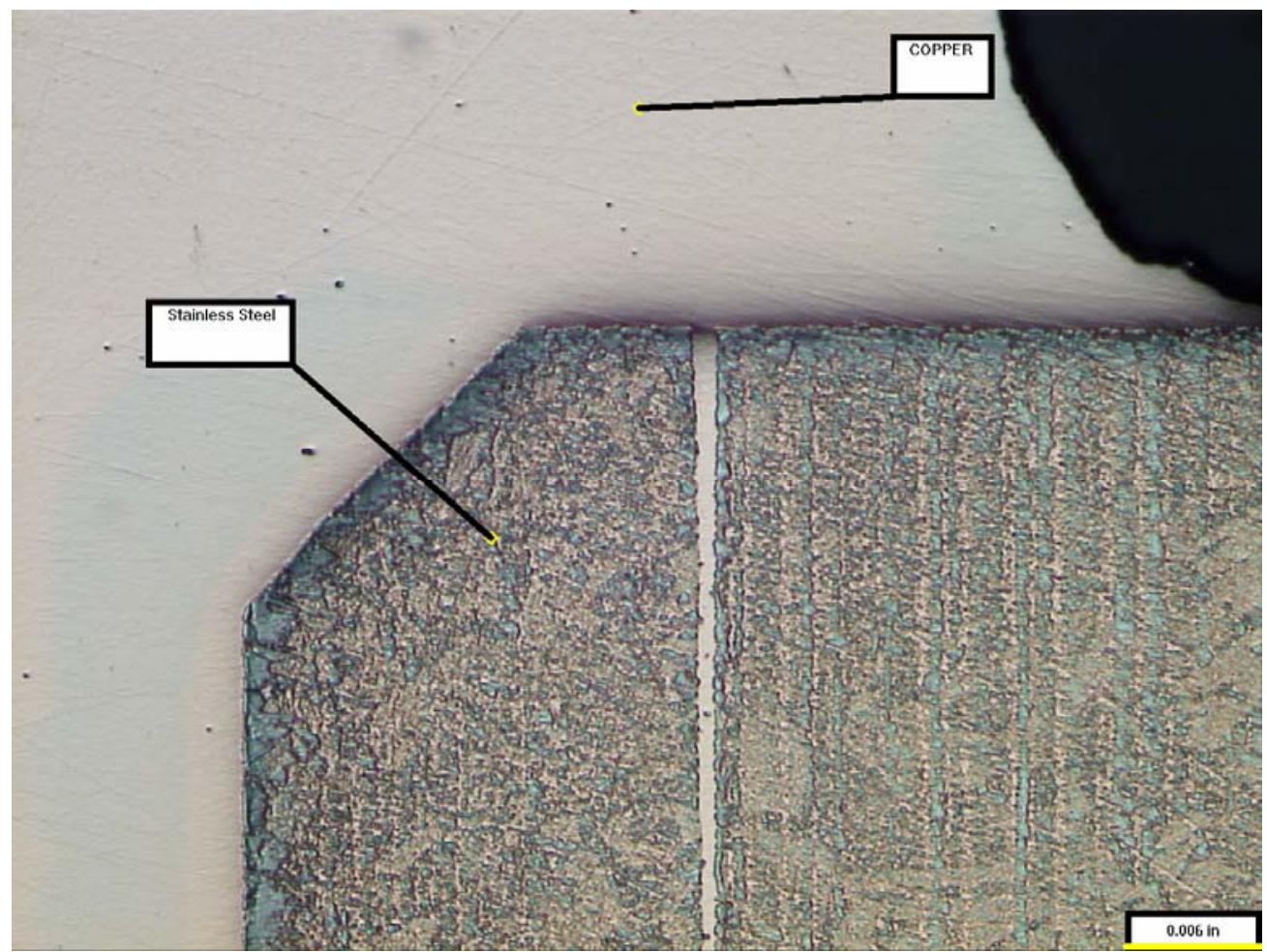

Photo 1: Stainless steel to copper joint 50x

Metallographic analyses of the different braze joints showed no internal operational damage or external environmental effects. Atmospheric corrosion occurs when a thin film of electrolytic solution, such as water, condenses on a metal surface. The humidity content of the air is a critical parameter in determining corrosion activity. Lack of surface corrosion indicates the operating relative humidity of this section was sufficient to yield a negligible corrosion rate. In addition, there was no visible corrosion due to galvanic coupling at the copper-347 stainless, copper-304 stainless or copper-CuAu interfaces.

\section{Cavity Cylinder Stack}

The cavity cylinder stack is brazed to the input coupler assembly that consists of an alternating series of discs (PF 750-150) and cavity cylinders (PF 750-179). These two 
parts were joined with a braze alloy composition of 65\% copper and 35\% gold. A cell consists of one cylinder and 2 discs brazed at each end. Cell 1 is closest to the end flange assembly next to the input coupler. Disc 1 brazed to cylinder 1 had the largest inside diameter and disc 85 (brazed to cylinder 84) had the smallest inside diameter.

The region between cells 11 through 21 was selected for analysis. Thirty-six braze joint samples were sectioned from the top (up) and bottom locations from every other cell assembly. Cell range 17 to 21 was fully covered, on the atmospheric side, by Mu-Metal shielding. Mu-Metal is a common trade name for a series of high magnetic permeability metals whose composition is about $75 \%$ nickel with small amounts of molybdenum, copper, and iron. Cell range 11 through 15 was uncovered.

Metallographic analyses of the different braze joints showed no internal operational damage or external environmental effects. The surface condition of the braze joint covered by the Mu-Metal was very similar to the uncovered condition. The surface oxidation of the internal cavities became darker with the distance from input coupler.

\section{Cooling Water Tubing and Fittings}

Eight copper water-cooling tubes were brazed to the periphery of the 10-foot section of waveguide. The water-cooling tubes were required to keep the accelerator section at a constant temperature of $113^{\circ} \pm 1.25^{\circ} \mathrm{F}$. The 8 serpentine tubes are fed with water from the section midpoint. Braze filler metal used for attaching the tubes and fittings consisted of $62 \%$ silver, $24 \%$ copper, and $14 \%$ indium. The water source was recirculated low conductivity water (LCW).

The inside wall of the hairpin cooling tubes (PF 751-044) and tee fittings (PF 751-037) were coated with a tough, black film that was primarily CuO. The tubing was OFHC copper $1 / 2$ " O.D. x 0.080 " wall. The Tee fitting was OFHC copper with ID dimensions of .340" x .628" x .340". Nominal wall thickness for the center connection was $0.040 "$ and 0.0245 " for the thinnest locations on the two branches. Uniform corrosion was observed on all internal surfaces exposed to the LCW.

\section{Tubing}

External surface oxidation of the cooling tubes (PF 751-044) was visible by metallographic analysis at 200x magnification. Environmental corrosive attack occurred along surface grain boundaries to a depth of .003". See Photo 2 on next page. General pitting was not observed on internal tubing walls. Wall thickness measurements were made in numerous locations on several different tube sections. The original nominal wall was .080" thick. The thinnest wall thickness was found to be $0.051 "$. 


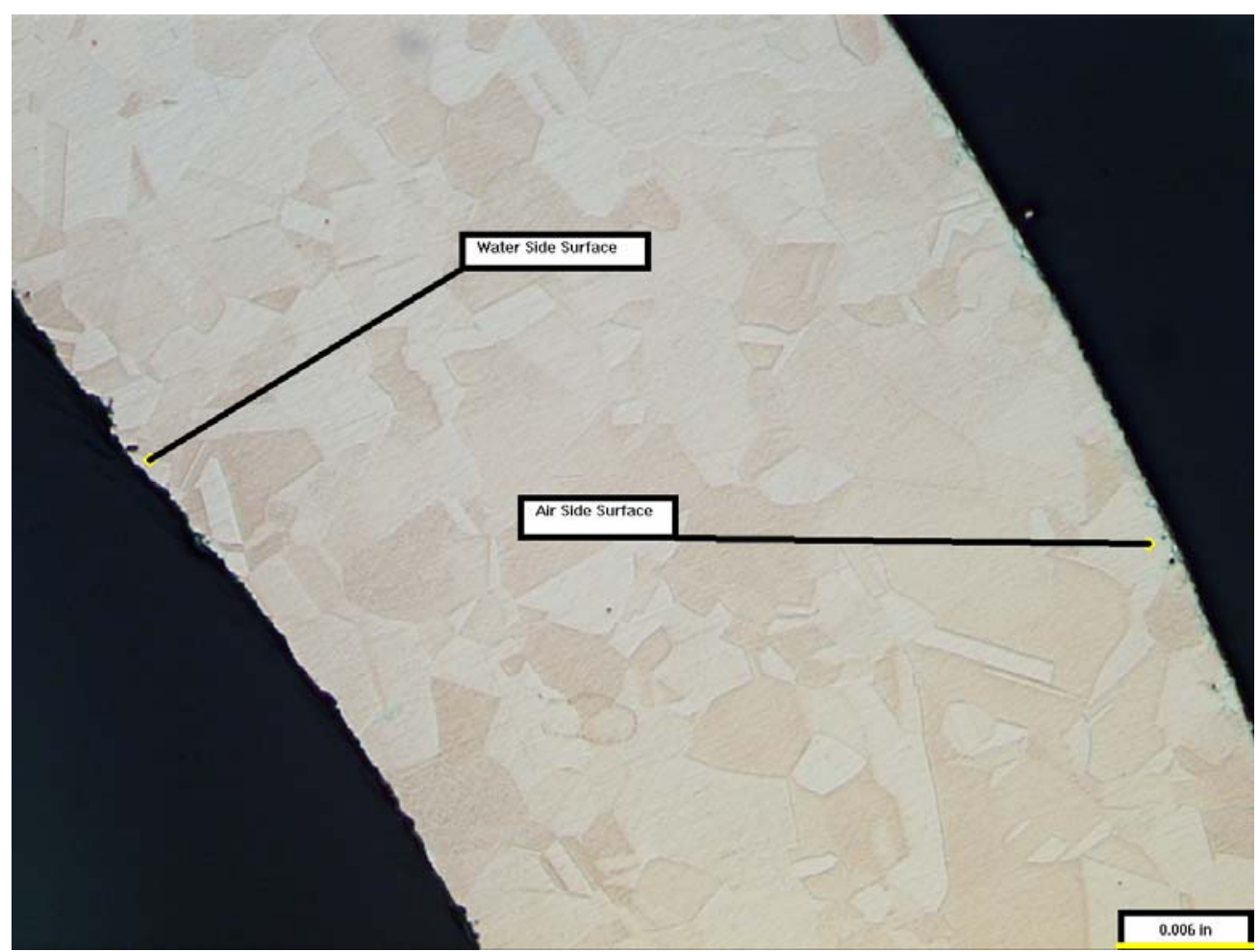

Photo 2: Internal surface of cooling water tube 50x Note evidence of uniform corrosion on both surfaces

\section{Fittings}

Tee fittings (PF 751-037) joined the cooling water inlet and outlet feed tubes (PF 751043) to the eight hairpin cooling tubes (PF 751-044). Each tee contains 3 braze joints. The joints did not show evidence of corrosion or erosion but contained localized porosity, which occurred during the manufacturing process. The internal walls of the tee showed uniform corrosion and pitting. Wall thickness varied by location. The center stem wall of .040" decreased to .029" and contained pits to a depth of .010". In the region of the two branches, wall thickness decreased from .0245" to .020" with pitting to .003". Inlet and outlet tee wall condition did not vary with flow direction. See photos 3 and 4 on next page for pitting morphology. 


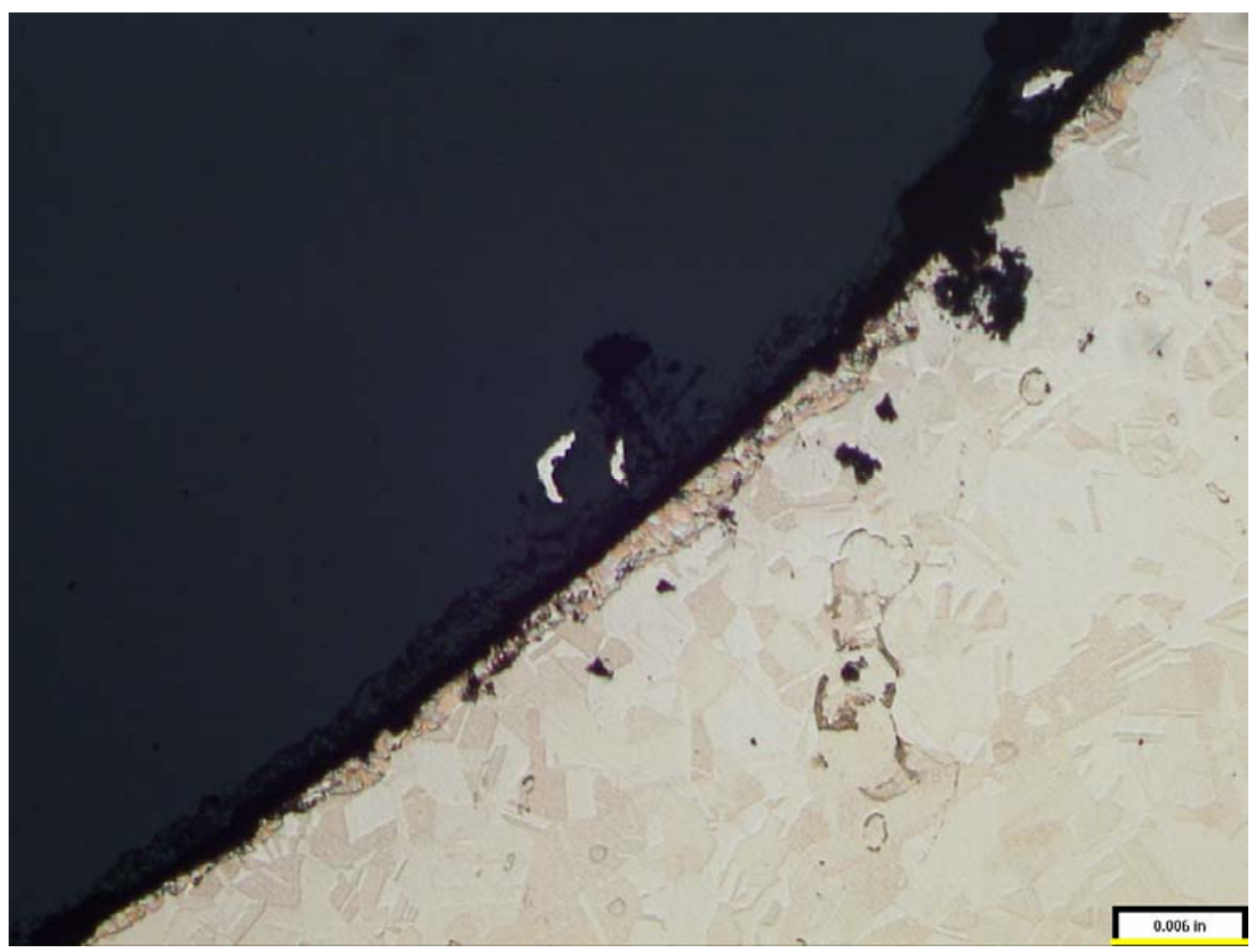

Photo 3: Internal surface of outlet Tee with pitting corrosion 50x

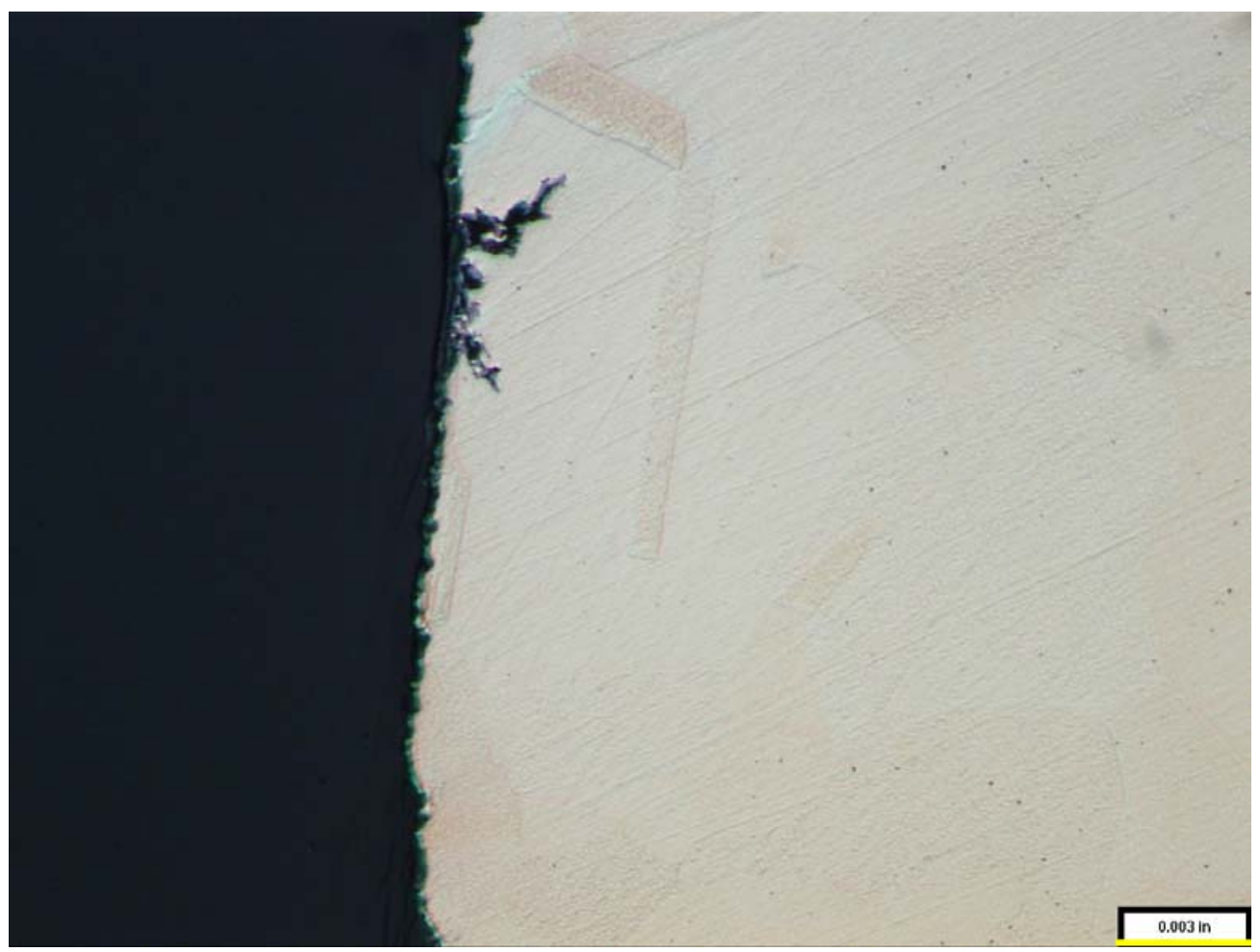

Photo 4: Internal surface of outlet Tee with pitting corrosion 100x 


\section{General Corrosion Rate}

Weight loss analysis, per ASTM G1, was used to determine the general corrosion rate of the water jacket cooling system. ASTM G1 defines the standard practice for preparing, cleaning and evaluation of corrosion test specimens.

An unused 1" long piece of tube was selected and compared to a 1" section that had been in service for more than 30 years. The used piece was cleaned of all corrosion products. The weight of new copper tube ( 0.080 " wall) was 15.49 grams and the weight of used copper tube (0.051" wall) was 10.56 grams.

$\mathrm{W}=$ Weight loss $=4.93$ grams

$\mathrm{D}=$ Copper density $=8.96 \mathrm{gr} / \mathrm{cm}^{3}$

$\mathrm{A}=$ Exposed internal service area $=1.1618 \mathrm{in}^{2}$

$\mathrm{T}=$ Exposure time $=269,280$ hours

$\mathrm{K}=$ Unit conversion constant $=5.34 \times 10^{5}$

$$
\text { Rate }=\frac{(W \times K)}{(D \times A \times T)}=0.939 \text { mils } / \text { year }
$$

\section{Pressure Rating and Allowable Stress}

It would be helpful to estimate the remaining life of the copper tubing and fittings. The LCW supply pressure is 250 psi and return pressure is 50 psi based upon SPEAR 3 upgrade data. Hairpin tubing corrodes at a rate of about $1 \mathrm{mil}(.001 \% / \mathrm{year})$ and the Tee fitting at approximately 0.3 mils (.0003"/year). The allowable internal pressure for copper tubing in service is based on the Barlow formula for thin wall, hollow cylinders used in ASME B31 Code for Pressure Piping. The allowable pressure can be determined by the Barlow formula where:

$\mathrm{P}=$ allowable pressure (psi)

$\mathrm{S}=$ allowable stress for annealed copper up to $100^{\circ} \mathrm{F}$ service $=6000 \mathrm{psi}$

$\mathrm{t}=$ wall thickness (inches)

$\mathrm{D}=$ diameter (inches)

$$
P=\frac{(2 \times S \times t)}{(D-(.08 \times t))}
$$

The value of $S$ is the allowable design strength for continuous long term service of tubing, as determined by the ASME Boiler and Pressure Vessel Code, Section 1Materials. Annealed ratings were used since the entire structure was subjected to several braze cycles. The weak link in the system appears to be the thin walls of the tee fitting. The specific location is about $1 / 8$ " long on the branch stem next to the tubing-tee braze joint. The LCW supply pressure of 250 psi will exceed allowable fitting pressure in about the year 2027. 
Table I. Estimate of allowable pressure in cooling water tubing as wall thickness decreases due to uniform corrosion

\begin{tabular}{|l|c|c|c|c|}
\hline Description & S (psi) & t (inches) & D (inches) & $\begin{array}{c}\text { Allowable } \\
\text { Pressure (psi) }\end{array}$ \\
\hline Tubing 1966 & 6000 & 0.08 & 0.5 & 1945 \\
\hline Tubing 1997 & 6000 & 0.051 & 0.5 & 1234 \\
\hline Tubing 2006 & 6000 & 0.042 & 0.5 & 1015 \\
\hline Tubing 2020 & 6000 & 0.028 & 0.5 & 675 \\
\hline Tubing 2027 & 6000 & 0.021 & 0.5 & 506 \\
\hline
\end{tabular}

Table II. Estimate of allowable pressure in cooling water fittings as wall thickness decreases due to pitting and corrosion

\begin{tabular}{|c|c|c|c|c|}
\hline Description & S (psi) & $\begin{array}{c}\text { t (inches) } \\
\text { Thinnest location }\end{array}$ & D (inches) & $\begin{array}{c}\text { Allowable } \\
\text { Pressure (psi) }\end{array}$ \\
\hline Tee fittings 1966 & 6000 & 0.0245 & 0.389 & 760 \\
\hline Tee fittings 1997 & 6000 & 0.017 & 0.389 & 526 \\
\hline Tee fittings 2006 & 6000 & 0.0143 & 0.389 & 442 \\
\hline Tee fittings 2020 & 6000 & 0.0101 & 0.389 & 312 \\
\hline Tee fittings 2027 & 6000 & 0.008 & 0.389 & 247 \\
\hline
\end{tabular}

\section{Conclusion}

The aim of this study was to determine the integrity of an accelerator section after prolonged operation. Bulk metallographic analysis was used to examine the 30 year old braze joints and critical point sites of the LCW cooling system.

The end flange assembly showed no internal operational damage, galvanic corrosion or external environmental effects.

The cavity cylinder stack showed no internal operational damage or external environmental effects. The internal surface was highly oxidized.

The internal cooling water tubing is uniformly corroding at a rate of about 1 mil per year. The tee fittings have good braze joints however the internal surfaces are corroding at nonuniform rates due to general corrosion and pitting. The LCW supply pressure of $250 \mathrm{psi}$ will (approximately) exceed allowable fitting pressure in the year 2027. 